Revista Destaques Acadêmicos, Lajeado, v. 11, n. 4, 2019. ISSN 2176-3070

DOI: http://dx.doi.org/10.22410/issn.2176-3070.v11i4a2019.2347

http://www.univates.br/revistas

\title{
METODOLOGIA DE CRIAÇÃO E ANÁLISE ESTRUTURAL DE UM PÓRTICO BI APOIADO
}

\author{
Amanda Strohaecker ${ }^{1}$, Henrique Scalcon Branchier² ${ }^{2}$ Joeser Guimaraes ${ }^{3}$, \\ Tuanny Rabaiolli Ramos ${ }^{4}$
}

\begin{abstract}
Resumo: A engenharia estrutural tem avançado ao longo do tempo, criando diferentes formas de análise. Por conta dos diferentes materiais que podem ser utilizados na construção civil, a combinação destes métodos impacta no comportamento das estruturas reais. Visando à pesquisa científica e tecnológica sobre novos métodos construtivos, a competição de Aparato de Proteção ao Ovo (APO) foi criada. O aparato é um pórtico de concreto feito para proteger um ovo durante o processo de ruptura da estrutura, na qual são aplicadas cargas a partir de determinadas alturas. É necessário que a argamassa de concreto utilizada na concretagem tenha bom desempenho, associada ao uso dos fios de aço mola, respeitando os métodos construtivos previstos em regulamento, para que alcancem resistência máxima. Para isso, é imprescindível um estudo da interferência de forças sobre uma estrutura e a pesquisa sobre materiais e seus elementos. A partir do arranjo perfeito, dá-se a concepção de uma peça de concreto com características que atendam sua demanda construtiva. Este estudo é um relato de experiência sobre a metodologia utilizada para a obtenção de um pórtico de concreto armado em miniatura para a competição do Centro de Ciências Exatas e Tecnológicas - CETEC, da Universidade do Vale do Taquari - Univates. Obteve-se, neste concurso, bons resultados, com uma estrutura que resistiu ao impacto de um golpe a 2,5 metros de altura, respeitando as exigências com relação às medidas de projeto.
\end{abstract}

Palavra-Chave: Concurso. Concreto. Pórtico. Aparato. CETEC.

1 Universidade do Vale do Taquari-UNIVATES.

2 Universidade do Vale do Taquari-UNIVATES

3 Universidade do Vale do Taquari-UNIVATES

4 Universidade do Vale do Taquari-UNIVATES 


\section{Introdução}

A necessidade de reduzir custos mantendo qualidade e a racionalização de materiais em canteiros de obras, motivou na construção civil o avanço tecnológico da engenharia estrutural. As pesquisas baseadas no uso do cimento Portland como sendo um aglomerante importante ao ser adicionado no traço de concretos e argamassas, juntamente com adição de aditivos e fibras e a soma do uso de softwares voltados a esta área, tornaram o processo construtivo de estruturas de concreto armado mais eficaz.

O desenvolvimento de projetos, somados a vivência de problemas de caráter técnico caracterizam-se como uma considerável experiência para os acadêmicos dos cursos de engenharia civil. Segundo Rocha (2000), se considerarmos os aspectos estruturais, a formulação dos materiais que compõem a argamassa, acrescido da busca pelas tecnologias de construção mais eficazes e modernas, são estímulos para o aperfeiçoamento profissional. Somado a isso, tem-se o desenvolvendo do senso crítico e criativo dos estudantes. Este tipo de atividade, voltada a projetos é uma possibilidade de vivenciar o dia-a-dia do engenheiro, em situações em que o mercado de trabalho exige a compreensão dos diversos fatores que influenciam e impõem restrições aos processos construtivos. Espera-se que as dificuldades existentes sejam vencidas com empenho e conhecimento técnico científico.

Para resolver questões estruturais são utilizadas técnicas numéricas que, associadas ao método das forças, permitem alcançar respostas da estrutura além dos pontos críticos. Rocha (2000) explica que essas técnicas são estratégias que analisam o incremento de carga e de iteração. Assim, essas técnicas de solução não-linear permitem observar o comportamento completo da trajetória de equilíbrio da estrutura, chamada de curva carga-deslocamento. Como resultado, tem-se as regiões de ganho e de perda de rigidez, pontos de limites de carga e de deslocamento.

O projeto de um pórtico de concreto armado apresentado nesta pesquisa proporcionou observações quanto à segurança das estruturas e a influência do uso dos materiais na resistência dos elementos de concreto. Leva-se em consideração que é imprescindível a avaliação dos aspectos estruturais de deformação no comportamento das estruturas. segundo Galvão (2000). é o procedimento computacional que examina em sistemas estruturais complexos os aspectos mais relevantes do comportamento não-linear, permitindo obter estruturas mais esbeltas e seguras. O objetivo do trabalho era testar quais as influencias dos materiais - concreto, barras de aço e formato dos elementos agem sobre estruturas de concreto armado, impedindo ou não que essas estruturas cheguem ao rompimento total. 


\section{Abordagem Teórica}

O Comitê de Atividades Estudantis do Instituto Brasileiro do Concreto (IBRACON) realiza anualmente o concurso técnico chamado Aparato de Proteção ao Ovo (APO), sua finalidade é desafiar os estudantes de engenharia. A proposta consiste em projetar e construir um pórtico de concreto armado ou protendido, objetivando a proteção de um ovo contra os impactos lançados sobre a estrutura a partir de um cilindro metálico. Este estudo é um relato de experiência, baseado no concurso que foi desenvolvido no Congresso de Ciência e Tecnologia do Vale do Taquari, na Universidade do Vale do Taquari - Univates, e contribuiu no estímulo dos estudantes do curso de engenharia civil, desta instituição no desenvolvimento das habilidades características ao exercício desta profissão.

Segundo Vasconcelos (1985), o concreto é um material constituído por cimento, água, areia (agregado miúdo) e brita (agregado graúdo), podendo conter em sua mistura adições e aditivos químicos, melhorando ou modificando suas propriedades básicas. O concreto é obtido através do fracionamento em proporção dos materiais, o traço. Este, define a quantidade de cada um dos diferentes materiais, almejando características desejadas, tanto para o estado fresco quanto para o estado endurecido. Para Pfeil (1989), na construção de um elemento estrutural em concreto armado, além da mistura dos materiais, são necessárias as armaduras de aço, posicionadas em fôrma ou molde previamente, sucedidas pelo lançamento do concreto fresco que preenche a fôrma. Durante este processo realiza-se o adensamento do concreto, com intuito de envolver e aderir às armaduras. Após a cura, tempo de secagem, e outros cuidados durante o endurecimento do concreto e, por final, as fôrmas podem ser retiradas originando a peça de concreto armado.

Se comparado com outras estruturas, os materiais disponíveis para constituir o concreto são de fácil acesso e aplicação. Isto sugere a alta utilização de estruturas de concreto armado nos vários tipos de construção. Para Mehta (2008), edifícios com diversos pavimentos, barragens, pontes, viadutos, portos, reservatórios, entre outros são projetados com a qualidade do concreto, baixo custo, boa resistência, durabilidade e boa resistência à compressão. Juntamente com o aço e sua durabilidade, alta resistência a tração, permite a concepção de projetos de elementos de variadas formas e tamanhos. $\mathrm{O}$ envolvimento do concreto em torno do aço, protege-o contra corrosão e intempéries, desde que respeitado o cobrimento mínimo da armadura. Para tal, é necessário que haja aderência entre o concreto e o aço, criando um conjunto, na qual ambos trabalhem associados.

A principal norma para projeto de estruturas de concreto armado foi a NB 1, a qual teve última edição em 1978. Em 1980 teve sua nomenclatura substituída tornando-se NBR 6118. Em 2003, foi revisada e em 2007 reeditada. Em 2014, após novo processo de revisão, surgiu a quarta edição da NBR 6118, sendo esta a versão considerada neste texto. Esta norma trata apenas do projeto 
das estruturas de concreto armado e protendido, porque as recomendações para a execução das estruturas de concreto fazem parte da NBR 14931.

\section{Materiais e métodos}

Para a construção do APO foram utilizadas as análises com o software Ftool, seguindo as dimensões determinadas pelo edital do concurso. Utilizou-se de elemento de barra sólida com diâmetro de $50 \mathrm{~mm}$ e peso de $15 \mathrm{kgf}$, simulando a carga aplicada na estrutura, afim de aplicar os golpes sobre a estrutura. Como pode ser visto na Figura 1. Para dimensionamento de estruturas de concreto armado é necessário análise dos momentos máximos de deformação, a fim de pressupor o comportamento da estrutura quando em estado de desforma. Martha (2010) afirma que as ações sobre a estrutura devem ser combinadas, criando um ambiente de simulação gráfica que represente a situação mais desfavorável para a peça de concreto.

Figura 1 - Análise de carregamento aplicado em pórtico bi apoiado

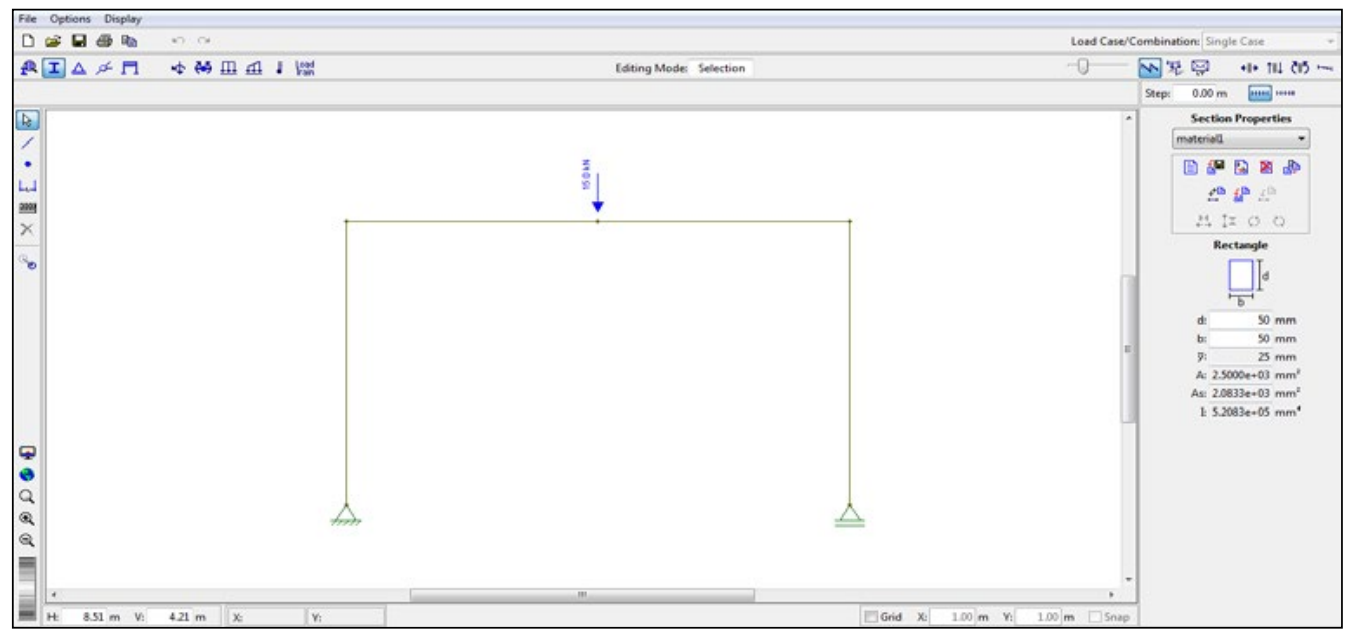

Fonte: Do autor.

Com relação ao efeito das cargas na estrutura, Hibbeler (2010) cita que os métodos de cálculo para uma estrutura devem considerar como as cargas externas influenciam no comportamento interno da peça de concreto. Para tanto, segundo o autor, é necessário o uso de uma ferramenta computacional, que possa auxiliar na compreensão da deformação até o ponto de ruína da estrutura, conforme indica a Figura 2. Desta forma, procura-se criar mecanismos que levem a sustentação máxima da composição estrutural, utilizando para tal as barras de aço. 
Figura 2 - Análise de deformação máxima em pórtico bi apoiado

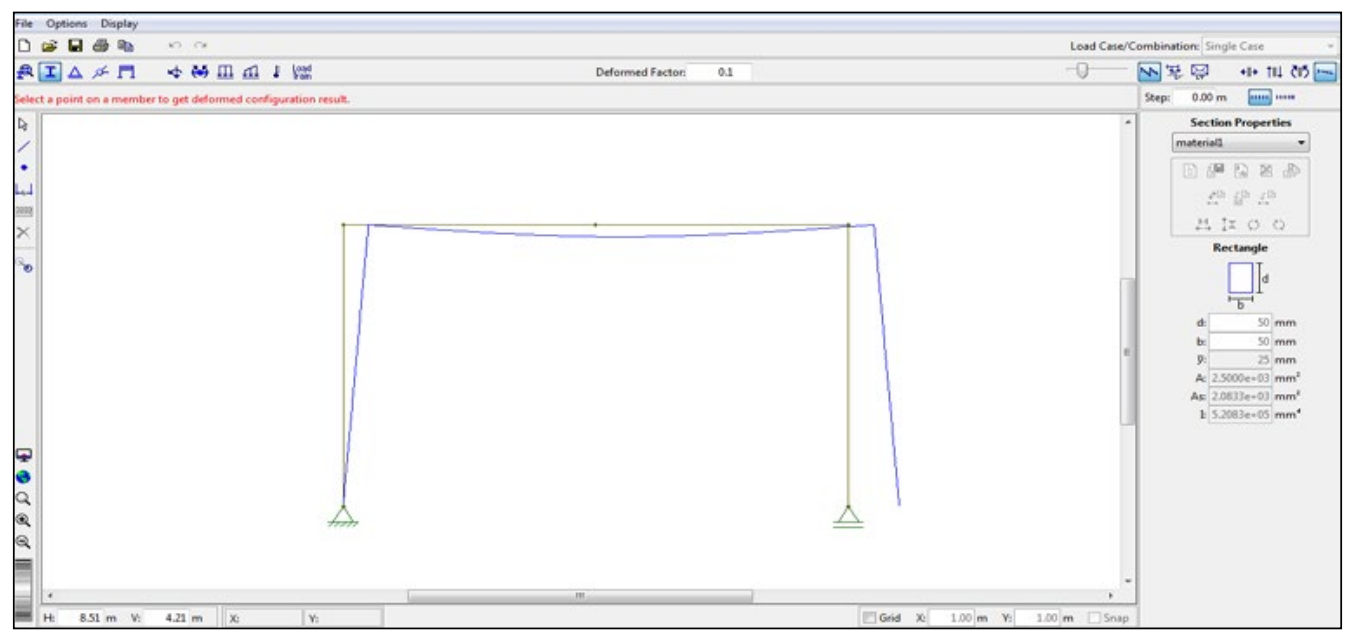

Fonte: Do autor.

Para determinar a forma do pórtico foram utilizadas as medidas descritas na norma do concurso e respeitados os limites máximos das medidas das seções dos pilares e da viga conforme Figura 3.

Figura 3 - Dimensões de projeto do pórtico em milímetros

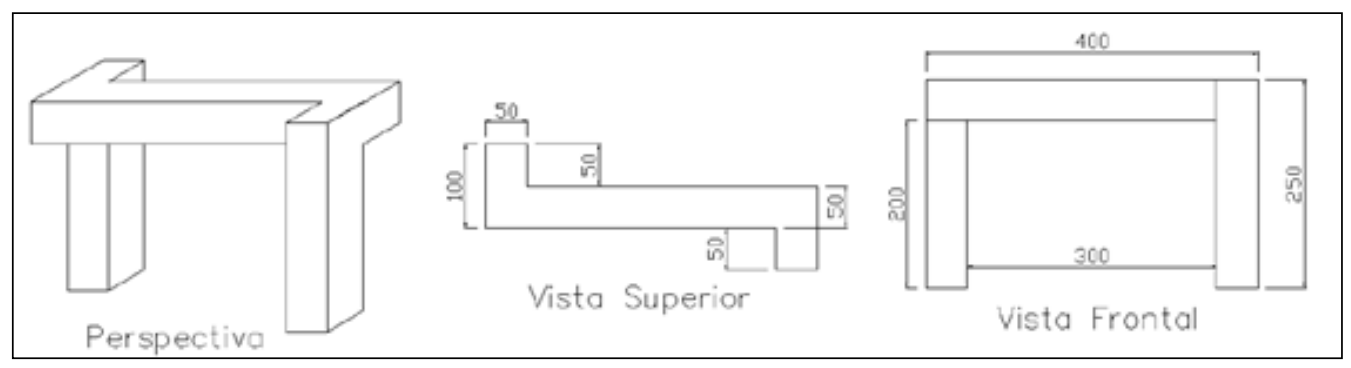

Fonte: Dos Autores, 2017.

Para a confecção da forma, utilizou-se placas de madeira com espessura de $18 \mathrm{~mm}$, unidas e parafusadas sobre uma base também de madeira. $\mathrm{O}$ uso dos parafusos teve como objetivo a facilidade para a desforma após a cura do concreto. Na elaboração da armadura, utilizou-se arame de aço-mola, tendo como matéria prima o aço temperado (FIGURA 4). Esse aço tem grande capacidade de armazenar energia mecânica, e possui alta resistência à fadiga e dureza. 
Figura 4 - Fôrma do pórtico e armadura

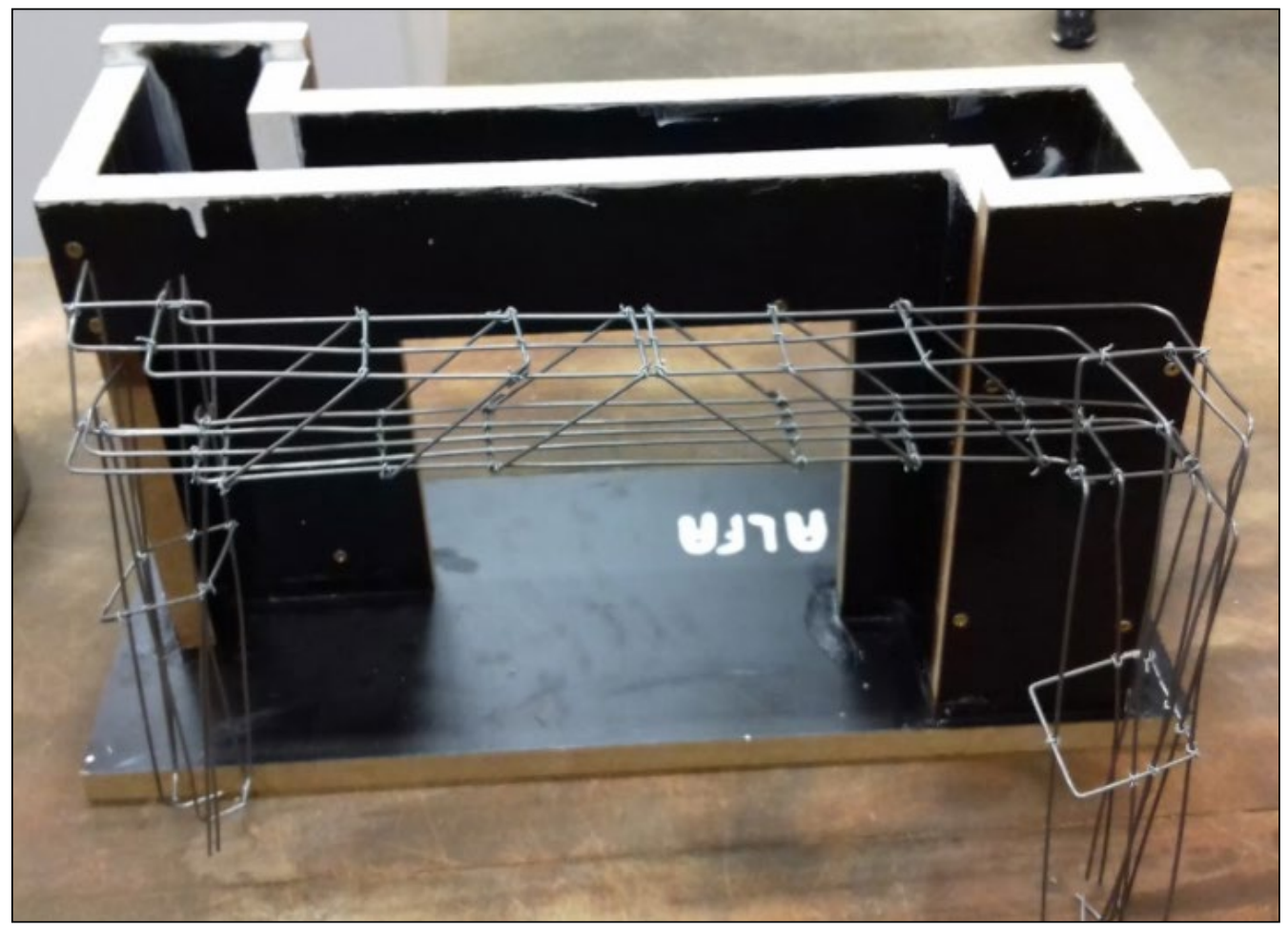

Fonte: Dos autores.

Com relação aos materiais que constituíram a mistura da argamassa de concreto, fez-se o uso de cimento, aditivos, areia, água e fibra de polipropileno. O cimento utilizado foi o CPII-F40 da marca Itaimbé, segundo o seu fabricante, este composto caracteriza-se pelo maior grau de finura, proporcionando maiores resistências em todas as idades de cura. É indicado para processos de desforma rápida bem como para uso em central de dosagem. Para o pórtico em questão, a desforma ocorreu no terceiro dia após a concretagem, o que demandou o uso de um cimento de alta reatividade, porém com uma cura cuidadosa.

Quanto aos aditivos, buscou-se o uso de aditivo polifuncional para concreto, após a mistura dos materiais. O fabricante do aditivo MIRA SET 27 da linha GRACE, líquido de cor marrom, recomendada a dosagem de 0,5 a $1 \%$, além disso,seu produto é indicado para uso em cimentos com elevado teor de adições, prolongando a manutenção do abatimento e melhorando as resistências. Ainda confere boa redução de água e facilita seu amassamento e adensamento, aumentando a fluidez por um tempo prolongado. Aumenta a coesão do concreto e proporciona melhor lançamento do mesmo. Ainda se fez uso de superplastificante de terceira geração da marca GRACE, Adva 518, indicado segundo seu fabricante para a concretagem de peças com alta 
resistência inicial e alto nível de trabalhabilidade. Além disto, este tipo de aditivo fornece alto índice de acabamento com poucos defeitos superficiais.

No que se refere ao uso dos agregados, compõem-se a argamassa com agregado miúdo, areia de diâmetro 2,4 mm e módulo de finura 1,51 fornecida por Maison Materiais de Construção. Os agregados miúdos são classificados como areias pois cerca de $95 \%$ do material pétreo passa pela peneira $4,8 \mathrm{~mm}$ de abertura normal. Além disto, foi utilizado microfibra de polipropileno junto a mistura, que são filamentos extremamente finosauxiliam a inibir o aparecimento de de fissuras e sua propagação na peça pois possui alto índice de retenção de água em seu interior.

Para a mistura dos materiais que formam o aparato, fez-se uso de uma argamassadeira com três velocidades, no qual os componentes foram adicionados seguindo uma ordem: 1 cimento, 1,048 areia, 0,72 água, 0,06 microfibra e aditivos ( 0,009 polifuncional e 0,17 superplastificante). Sendo a mistura colocada no molde e vibrada, a fim de diminuir o índice de vazios e evitar falhas de concretagem. Essa argamassa resultou em uma resistência à compressão de $75 \mathrm{MPa}$ aos vinte e oito dias.

\section{Resultados e discussão}

Durante o processo de ruptura, a aplicação da carga foi feita através de uma tubulação de 2,5 metros de altura. Aplicada a carga de 15 quilogramas a alturas de meio metro cada, como visto na Figura 5. Para constituir os apoios, foram necessárias amarras, por cordas elásticas e ganchos situados em uma peça moldada para receber o aparato, de acordo com a figura 5. Neste estudo em questão, foram utilizados fios de aço-mola, sem emendas. $\mathrm{O}$ teste era que a estrutura atingisse seu estado último de limite, objetivo do ensaio, romper a estrutura por completo.

Figura 5 - Aparato pronto para o rompimento e seu rompimento

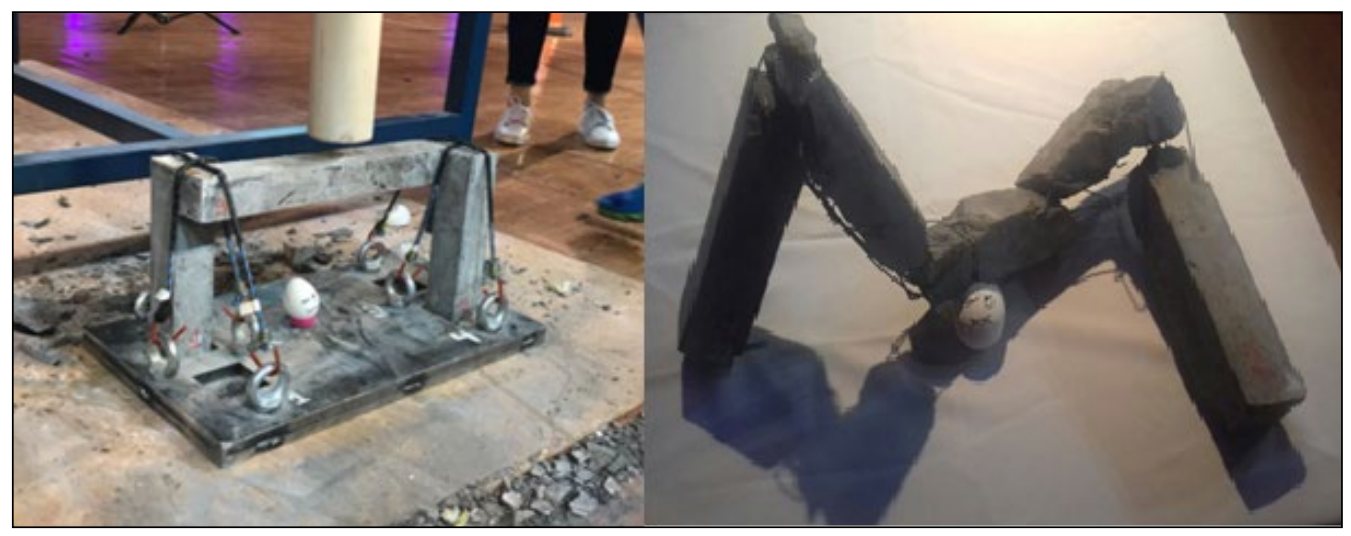

Fonte: Dos autores. 
De acordo com a quebra da estrutura, pode-se perceber que alguns pontos foram mais suscetíveis a fissura e influenciaram na ruptura da mesma, devido ao aparecimento de deformações excessivas na peça por consequência da aplicação da carga concentrada no meio do vão. Na engenharia estrutural, segunda Martha (2010), o método que determina a carga máxima para qual a estrutura entra em colapso, considera a análise de tensões no regime linearelástico. Ao atingir o estado limite de ruptura, observou-se que as máximas tensões ocorreram na região medial da viga e nas regiões de conexão entre as colunas e a viga, Desta maneira, o giro é realizado e a ruptura acontece exatamente em cima do pilar, local onde a armadura deveria ter um reforço, de modo a impedir a força de translação.

No ponto médio da viga, foram distribuídos seis estribos amarrados aos fios de aço, com ângulo de quarenta de cinco graus cada, auxiliando no esforço cortante, e no momento fletor, quando ocorre esmagamento do concreto. Esperava-se que desta maneira as fissuras pudessem ser ocasionadas apenas nas extremidades, o que não ocorreu.

Conforme a disposição das armaduras na peça pode-se perceber dois fatores que contribuíram para seu rompimento. A disposição da armadura nas extremidades não ocorreu de forma homogênea e o fato de no ponto central da peça, onde foram aplicados os golpes, foram dispostas três barras na armadura negativa e cinco barras na armadura positiva. Presume-se que o ideal seria ter adotado apenas duas barras de armadura negativa, como armadura mínima de porta-estribo e seis barras longitudinais positivas, uma vez que o esforço gerado neste ponto da peça através das cargas é combatido pela resistência à flexão.

\section{Considerações finais}

As principais compreensões sobre esta pesquisa, foram norteadas pela análise estrutural do APO e pelos materiais que determinaram a composição final da argamassa e o seu papel no reforço estrutural. Os testes de carga realizados no software forneceram informações, ainda que muito precárias, sobre um possível comportamento que a estrutura sofreria após o teste de resistência. Contudo, também se levou em consideração o fato de que a argamassa com fibras fornecesse resistência suficiente para auxiliar a armadura.

Considerando o fato de que a estrutura em questão resistiu a cinco golpes, sendo o último a dois metros e meio de altura, o conjunto estrutural elaborado atendeu a demanda inicial proposta. Desta maneira, tornou o aparato resistente a um bom número de golpes. Entretanto, este resultado ainda não é o ideal. Seria necessário que a estrutura sustentasse mais um golpe aos dois metros e meio de altura, criando um sistema perfeito de proteção ao ovo.

Conclui-se nesta pesquisa, que novos testes deveriam ser feitos, comparando o uso de outros cimentos na argamassa, bem como uso de maior 
quantidade de fibras e ainda uma nova reformulação sobre o desenho ideal da armadura. Atendendo assim as questões mínimas estruturais e almejando sanar os pontos mais sujeitos ao rompimento identificados no primeiro teste.

\section{Referências}

COOK, R. D., Malkus, D. S., Plesha, M. E., Concepts and Applications of Finite Element Analysis, John Wiley \& Sons, 1989.

HIBBELER, R. C. Resistência dos Materiais. 7. ed. São Paulo: Pearson Prentice Hall, 2010.

MARTHA, L. F. Análise de estruturas: conceitos e métodos básicos. Rio de Janeiro: Elsevier, 2010.

MEHTA, P.K.; MONTEIRO, P.J.M. Concreto - Microestrutura, Propriedades e Materiais. São Paulo, Instituto Brasileiro do Concreto (IBRACON), 3a ed., 2008, 674p.

GALVÃO, A.S. (2000), “Formulações Não-Lineares de Elementos Finitos para Análise de Sistemas Estruturais Metálicos Reticulados Planos", Dissertação de Mestrado, Escola de Minas - UFOP, Ouro Preto, MG.

PFEIL, W. Concreto Armado, v. 1, 2 e 3, 5a ed., Rio de Janeiro, Ed. Livros Técnicos e Científicos, 1989.

ROCHA, G. Estratégias de incremento de carga e de iteração para análise não linear de estruturas. 2000. Dissertação (Mestrado em Engenharia Civil) - Universidade Federal de Ouro Preto, Escola de Minas, Departamento de Engenharia Civil, Ouro Preto.

VASCONCELOS, A.C. O concreto no Brasil - Recordes, Realizações, História. São Paulo, Ed. Pini, 2a ed., v.1, 1985, 277p. 